\title{
Musculoskeletal injuries among ERCP endoscopists in Canada
}

\author{
Sinead O'Sullivan BKin, Gary Bridge MSc(OT), Terry Ponich MD FRCPC
}

\section{S O'Sullivan, G Bridge, T Ponich. Musculoskeletal injuries among ERCP endoscopists in Canada. Can J Gastroenterol 2002;16(6):369-374.}

BACKGROUND: There are few reports in the literature describing musculoskeletal complaints among endoscopists, and none are specific to those who perform endoscopic retrograde cholangiopancreatography (ERCP).

PURPOSE: To examine the current practices of ERCP endoscopists and the prevalence of musculoskeletal injuries.

METHODS: A self-report survey was sent to physicians practising ERCP across Canada identified through a pre-existing database. A second mailing was sent six weeks later to those who did not respond to the first mailing.

RESULTS: Of 162 surveys sent, 122 responses were received, with five respondents indicating that they no longer performed ERCP and three declining to participate. Of the 114 participants, $67 \%$ reported at least one musculoskeletal complaint, and 58\% reported two or more complaints. Seventy-four per cent attributed their symptoms to endoscopy and/or ERCP, and 79\% reported that their condition was aggravated by performing ERCP. The most frequently reported pain symptoms were back pain $(57 \%)$, neck pain (46\%) and hand pain (33\%), which are all consistent with the physical risks involved in performing ERCP. Only $51 \%$ reported taking regular breaks, and only $25 \%$ reported having fluoroscopy tables with adjustable heights. The room designs of the respondents' ERCP facilities were analyzed for ergonomic considerations: $67 \%$ had poor ergonomics and $33 \%$ had good ergonomics. Sixty-four per cent reported that they were interested in learning preventive strategies.

CONCLUSIONS: Physicians who perform ERCP develop musculoskeletal injuries and are interested in learning about risk factor modification.

Key Words: Endoscopic retrograde cholangiopancreatography; Occupational injuries; Repetitive strain injuries

\section{Les lésions musculosquelettiques chez les endoscopistes CPRE au Canada}

HISTORIQUE : Quelques comptes rendus de la documentation scientifique décrivent des plaintes musculosquelettiques chez les endoscopistes, et aucune n'est propre aux endoscopistes qui effectuent des cholangiopancréatographies rétrogrades endoscopiques (CPRE).

OBJECTIF : Examiner les pratiques courantes des endoscopistes CPRE et la prévalence de lésions musculosquelettiques.

MÉTHODOLOGIE : Un sondage d'autoévaluation a été expédié aux

suite à la page suivante 
médecins effectuant des CPRE au Canada, repérés dans une base de données déjà existante. Un deuxième envoi a été acheminé six semaines plus tard à ceux qui n'avaient pas répondu au premier.

RÉSULTATS : Sur les 162 sondages postés, 122 ont été renvoyés. Cinq répondants ont affirmé ne plus exécuter de CPRE, et trois ont refusé de participer. Par conséquent, un total de 114 participants ont répondu au questionnaire, pour un taux de réponse de $74 \%$. Soixante?sept pour cent d'entre eux ont fait état d'au moins un trouble musculosquelettique, et $58 \%$ d'au moins deux de ces troubles. Soixante?quatorze pour cent attribuaient leurs symptômes aux endoscopies ou aux CPRE, et $79 \%$ ont déclaré que leur état était aggravé par l'exécution des CPRE. Les douleurs les plus courantes étaient les maux de dos (57\%), les cervicalgies (46\%) et les douleurs aux mains (33\%), toutes compatibles avec les risques physiques reliés à l'exécution de CPRE. Seulement $51 \%$ des répondants ont affirmé faire des pauses régulières, et seulement $25 \%$ ont précisé que la hauteur des tables de fluoroscopie était réglable. L'ergonomie de la conception des salles de radioscopie dans lesquelles les répondants effectuent les CPRE a été analysée. L'ergonomie de $67 \%$ d'entre elles laissait à désirer, tandis que celle de $32 \%$ des autres était bien conçue. Soixante?quatre pour cent des répondants ont déclaré être intéressés à connaitre des stratégies de prévention.

CONCLUSIONS : Les médecins qui effectuent des CPRE peuvent présenter des lésions musculosquelettiques et sont intéressés à connaître des moyens de modifier les facteurs de risque.
$\mathrm{O}_{\mathrm{s}}^{\mathrm{c}}$ ccupationally induced musculoskeletal injuries have become a widespread problem among many health care professionals (1-6). The two areas of the body that are most frequently affected by these occupational injuries are the lower back and the upper extremities. Repetitive movements, static muscle loading and awkward body posture are the most common causes of musculoskeletal injury (7). Evidence suggests that physicians incur occupational injuries by performing procedures on a repetitive basis. In addition, a positive correlation between wearing lead aprons and developing low back injury has been shown $(8,9)$. Despite this evidence, very little has been reported regarding musculoskeletal injuries to endoscopists, and there is no literature specific to the injuries incurred by those who perform endoscopic retrograde cholangiopancreatography (ERCP). 'Endoscopist's thumb', 'endoscopist's tendonitis', 'endoscopist's neck' and 'biliary endoscopist's knuckle' are all conditions that have been attributed specifically to the performance of endoscopy procedures, but no studies have been conducted to determine the prevalence of such conditions (10-14).

In a study conducted in Indiana, of 400 endoscopists surveyed, $84.6 \%$ were found to be troubled by a musculoskeletal condition while working. The most common condition was back pain, and longer endoscopy hours were positively correlated with the development of musculoskeletal injuries (15). This study did not differentiate ERCP from other endoscopy procedures, and the authors thought that, given the additional risks involved in ERCP, the endoscopists who performed them were particularly vulnerable to the development of musculoskeletal injuries.

Endoscopy procedures are repetitive, are usually performed standing and involve holding heavy pieces of equipment upright (14). ERCP, a complex endoscopic procedure, is conducted under fluoroscopic guidance and thus imposes additional stresses on the operator.

More advanced equipment, along with increasing physician familiarity with the technique of ERCP, has led to increasingly complex therapeutic procedures. The result is that the physician must maintain static positions and strained postures for long periods of time, with the imposed physical load of both the endoscope and the lead apron. Furthermore, ERCPs are usually performed in cramped radi- ology facilities that have not been designed for ERCP. Thus, poor ergonomic design of facilities is another potential concern.

The purpose of the present study was to determine the extent of occupationally induced musculoskeletal injuries among ERCP endoscopists, and to describe the current practices to determine the potential risk factors of such conditions. Furthermore, we aimed to describe protective measures and to make suggestions for reducing the risk of developing these types of injuries.

\section{METHODS}

Physicians practising ERCP in Ontario were identified from a pre-existing database obtained by calling all hospitals with 100 or more beds. Physicians practising ERCP outside of Ontario were identified by calling ERCP endoscopists at each medical school in Canada, who then identified their local academic and community peers. A study package containing a cover letter, a two-page self-administered questionnaire and a stamped return envelope was mailed to the identified physicians. The return envelopes were numbered to keep track of who participated in the study. The results were kept anonymous. Nonrespondents were sent a second study package, with the same contents as the first mailing, approximately six weeks later.

\section{Questionnaires}

To increase the response rate, the questionnaire was kept as short as possible - one page printed on both sides. The physicians were asked about their ERCP practices. How long the physicians had been practising ERCP and how many ERCPs were performed annually were recorded (Table 1). Questions about whether the physicians experienced any musculoskeletal condition were followed by more questions related to their conditions. Physicians were then asked questions related to the physical risks involved in performing ERCP: the type of lead apron worn, the type of endoscope used (video versus fibre optic) and the frequency of breaks (defined by removing the lead apron between procedures). For ergonomic considerations, they were asked to include a sketch of their own radiology facilities. Physicians were also asked to rank a list of possible physical risk factors to the operator. Finally, physicians were 
TABLE 1

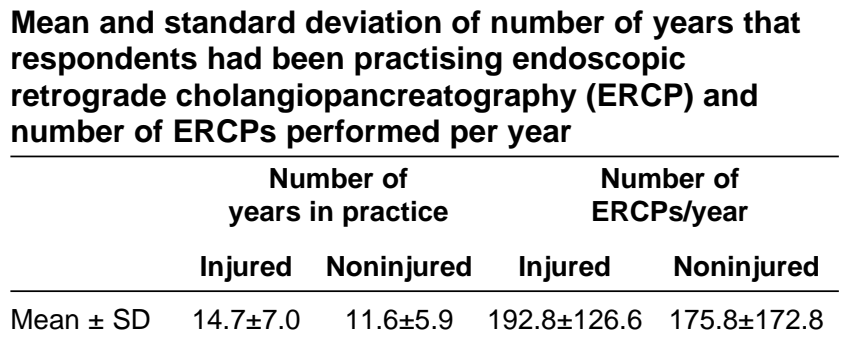

asked whether they were interested in receiving an ergonomic assessment or learning more about preventive strategies related to ERCP. To keep the survey brief and the response rate high, questions did not involve details regarding work-up or diagnosis, or physicians' musculoskeletal complaints. Pain symptoms were assumed to be related to repetitive strain injuries (RSIs), which is a general term covering a group of conditions that are all related to the wear and tear on the soft tissues of the body.

\section{Design and statistical considerations}

This was a cross-sectional, questionnaire-based, descriptive study. Results are primarily expressed as a percentage of the responses received. Nonparametric tests of significance, $Z$-tests and $\chi^{2}$ tests were also performed on selected variables to compare respondents who reported having injuries with those who did not.

\section{RESULTS}

Of the 162 surveys sent, 122 responses were received, with five respondents indicating that they no longer performed ERCP and three indicating that they were not interested in participating. This is a total response rate of $74 \%$ (114 of 154).

Sixty-seven per cent of respondents reported at least one musculoskeletal complaint, $58 \%$ of whom reported two or more complaints. Back pain (57\%), neck pain $(46 \%)$ and hand pain $(36 \%)$ were the complaints reported most frequently, followed by elbow pain (8\%), shoulder pain (16\%) and other complaints (two wrist pain, one heel pain and one latex allergy) (5\%). Forty-one per cent of the affected respondents experienced their symptoms while performing ERCP and during other activities, and another 38\% of the affected respondents were bothered by their symptoms only when performing ERCP. Three-quarters (74\%) of affected respondents felt that their conditions were attributable to endoscopy and ERCP. Seventeen per cent thought that their injury was due to sports, $4 \%$ thought that their condition was due to their operating table, $4 \%$ thought that their injury was due to a pre-existing condition and $1 \%$ thought that their condition was simply a factor of age.

The majority of respondents had been afflicted with their pain symptoms within the past five years (Table 2). Almost one-half $(45 \%)$ of the respondents who had an injury or pain symptoms did not use any form of treatment.
TABLE 2

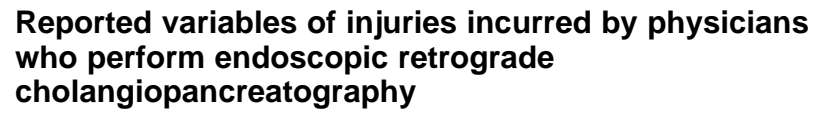

\begin{tabular}{lc}
\hline Variable & $\begin{array}{c}\text { Number of } \\
\text { responses (\%) }\end{array}$ \\
\hline Number of years afflicted with symptoms $(\mathrm{n}=72)$ & \\
$0-5$ & $40(56)$ \\
$6-10$ & $23(32)$ \\
$11-15$ & $5(7)$ \\
$16-20$ & $4(6)$ \\
Type of treatment used ( $\mathrm{n}=76)$ & \\
None & $34(45)$ \\
Medication & $27(36)$ \\
Surgery & $6(8)$ \\
Chiropractic treatment & $8(11)$ \\
Physiotherapy & $11(15)$ \\
Massage therapy & $10(13)$ \\
Acupuncture & $4(5)$ \\
Rest & $8(11)$ \\
Other & $4(5)$ \\
Frequency of breaks $(\mathrm{n}=114)$ & \\
Regular breaks between procedures & $58(51)$ \\
Occasional breaks between procedures & $15(13)$ \\
No breaks between procedures & $39(34)$ \\
\hline
\end{tabular}

Of the treatments used, the most common was medication (36\%), followed by physiotherapy (15\%) and massage therapy $(13 \%)$. Thirty-three per cent of respondents used more than one form of treatment (Table 2). Respondents who had an injury were asked whether they had modified the way in which they performed ERCP to prevent further injury or to alleviate pain symptoms while performing ERCP. Of the 76 injured respondents, 14 (18\%) had modified how they performed ERCP, three stated that conditions could not be modified and the remaining 59 had not attempted to change their working conditions. The majority of respondents (61\%) wore a one-piece lead apron while performing ERCP. Seventy-nine per cent of respondents currently used a videoscope, while $11 \%$ currently used fibre optic scopes. Eighty-nine per cent of respondents had used fibre optic scopes in the past. More than one-half of the respondents did not take regular breaks between procedures (Table 2).

The ergonomic room designs of all the respondents' ERCP facilities, as per sketches completed in the survey, were analyzed by a kinesiologist and an occupational therapist, and placed into two categories - 'poor' (67\% of respondents) and 'good' (33\% of respondents). Seventy-four per cent of respondents reported having tables without 


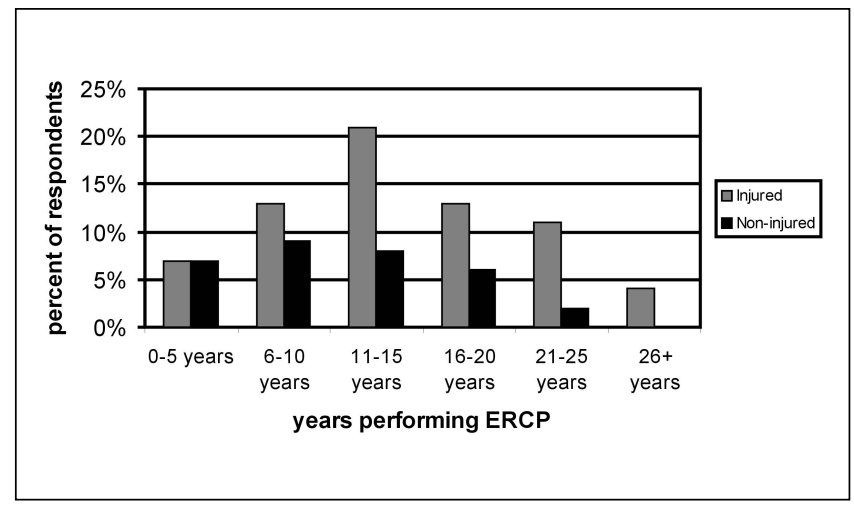

Figure 1) Number of years that respondents had been practising endoscopic retrograde cholangiopancreatography (ERCP). Respondents with assumed repetitive strain injuries were compared with those without injuries. A higher proportion of injured physicians was seen among those who had been performing ERCPs for greater lengths of time. Statistical analysis revealed this factor to be significant

adjustable heights, 25\% reported having fluoroscopy tables with adjustable heights and $1 \%$ did not know whether their tables were adjustable. Respondents were asked about sports and other leisure activities outside of work, and none of the activities were consistent with the injuries; $84 \%$ of respondents were classified as 'active' and 16\% were classified as 'sedentary'.

The majority of respondents (64\%) were interested in learning more about risk factor modification during ERCP and/or having an ergonomic assessment of their work environment. One per cent of respondents had already had an ergonomic assessment of their workplace.

\section{Statistical analysis}

Respondents were subdivided into two groups - 'injured' and 'noninjured'. Nonparametric tests of significance were performed. Z-tests were performed to determine the statistical significance of number of years performing ERCP, number of ERCPs performed per year and number of ERCPs performed in succession; the corresponding $\mathrm{Z}$-scores were $2.442,0.525$ and 0.655 , respectively. Therefore, the only significant variable (Z-score greater than 1.654) was number of years performing ERCP.

$\chi^{2}$ tests were performed to determine the statistical significance of having adjustable tables and ergonomic room design between injured and noninjured respondents on developing an injury. Of these two factors, only ergonomic room design had a statistically significant effect on injury, with a calculated value of 2.534 , which was greater than the critical value for $\mathrm{x}$.

\section{DISCUSSION}

Since 1992, the Occupational Safety and Health Administration has been preparing federal legislation in the United States concerning ergonomic hazards in at-risk workplaces (5). We are unaware of such legislation in Canada. Sufficient evidence and documentation of the

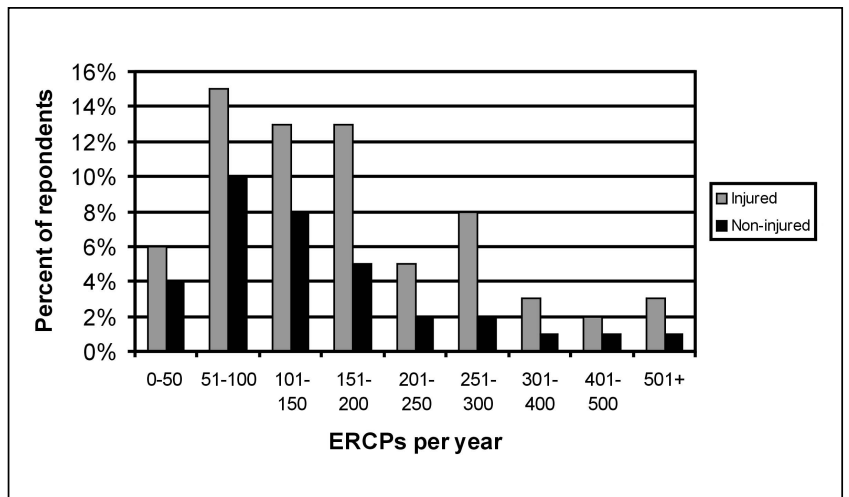

Figure 2) Number of endoscopic retrograde cholangiopancreatographies (ERCPs) that respondents performed per year. Respondents with assumed repetitive strain injuries were compared with those without injuries. Although a higher proportion of injured physicians was seen among those who performed more ERCPs per year, statistical analysis revealed that this factor was not significant

association between several health care professions and musculoskeletal disorders of the back and upper extremities have led to the implementation of various ergonomic considerations for such professions (5). Similar considerations need to be implemented for endoscopists who perform ERCP and other procedures on a repetitive basis. Until sufficient evidence and documentation demonstrate a need for risk management among endoscopists, no action will be taken to implement preventive strategies to protect the profession at large.

Back, neck and hand pain, respectively, were the most frequently reported symptoms and are all consistent with the physical risk factors involved in performing ERCPs leading to RSIs. A total of $79 \%$ of injured respondents were bothered by their symptoms while performing ERCP, and $74 \%$ felt that their conditions were attributable to endoscopy and ERCP, suggesting the potential cause and effect relationship between ERCP and musculoskeletal injuries.

A comparison of physicians with musculoskeletal injuries and those without musculoskeletal injuries revealed a higher proportion of injured physicians among those who had been practising ERCP longer. This variable was significant. This finding is consistent with the finding that $56 \%$ of injured respondents had experienced their symptoms only within the past five years and that $88 \%$ had experienced their symptoms only within the past 10 years. Because the majority of the noninjured physicians had been practising ERCP for less than 10 years, they may not yet have developed symptoms. These types of injuries are cumulative trauma disorders, and a higher percentage of ERCP endoscopists may be afflicted over time (Figure 1). A higher proportion of injured physicians was also seen among those who performed more ERCPs per year (Figure 2). There were more injured physicians in every frequency category, but this was only statistically significant in those performing more than 150 ERCPs per year. 
TABLE 3

Summary of the risks and associated modification strategies for performing endoscopic retrograde cholangiopancreatography

\begin{tabular}{|c|c|c|}
\hline Risk factor & $\begin{array}{l}\text { Percentage of } \\
\text { respondents at risk }\end{array}$ & $\begin{array}{l}\text { Risk factor } \\
\text { modification strategy }\end{array}$ \\
\hline Ergonomic design of facilities & 58 & $\begin{array}{l}\text { Design should resemble that shown in Figure 3, promoting natural } \\
\text { postures and reducing the amount of twisting and bending }\end{array}$ \\
\hline Adjustable fluoroscopy tables & 75 & $\begin{array}{l}\text { Tables should have adjustable heights so that the operators can perform } \\
\text { procedures with their elbows in a neutral posture, gently flexed at } \\
\text { a } 90^{\circ} \text { angle }\end{array}$ \\
\hline Type of endoscope used & 11 & $\begin{array}{l}\text { Videoscopes are superior to fibre optic scopes, especially in the prevention } \\
\text { of neck injuries }\end{array}$ \\
\hline Type of lead apron worn & 61 & $\begin{array}{l}\text { Two-piece aprons should be worn to prevent unnecessary heavy physical } \\
\text { loads on the lower back and upper extremity }\end{array}$ \\
\hline Frequency of breaks & 34 & $\begin{array}{l}\text { It is essential to take breaks between procedures that require prolonged } \\
\text { standing and the maintenance of static postures, as in ERCPs }\end{array}$ \\
\hline $\begin{array}{l}\text { Type of treatment used for } \\
\text { musculoskeletal injuries }\end{array}$ & $\begin{array}{c}81 \\
\text { (45\% no treatment; } \\
36 \% \text { medication; } \\
15 \% \text { physical therapy) }\end{array}$ & Exercise is critical to reverse and prevent cumulative trauma disorders \\
\hline
\end{tabular}

Our data indicate that performing more procedures over time is positively correlated with musculoskeletal injury. Due to the vasoelastic nature of all biological tissues, the spine and other joints may develop residual deformation under static loads (16). Repeated load can result in cumulative fatigue, which decreases the ability of the joints - especially the spine - to bear future stress (16). Prolonged standing and bent-over postures increase the likelihood of developing low back pain (17), and are both characteristics of physicians who perform ERCP. Twisting and bending motions drastically increase forces throughout the spine. Facilities that are designed to promote natural postures and limit the amount of twisting and bending protect operators from the development of cumulative trauma disorders. The risk factors involved in performing ERCP, the survey results and the appropriate modification strategies are summarized in Table 3 .

Sixty-four per cent of respondents were interested in having their workplace ergonomically assessed or in receiving preventive information regarding risk factor modification. Job analysis involves a basic ergonomic survey of the general physical environment, and a detailed assessment of the work site and task demands. The physical demands of a task include the force, repetition and hand position required (18). Repetition and hand position are two factors that are of particular concern for ERCP endoscopists. Overall work pace and the frequency of breaks are also significant determinants of potential musculoskeletal injury (18). One-half of respondents reported that they did not take regular breaks between procedures, and most ERCP endoscopists perform other endoscopy or surgical procedures when they are not performing ERCP.
Intrinsic factors such as poor posture and low fitness level also play a role in the acquisition of RSI. Respondents were classified as active or sedentary based on an analysis of leisure activities. This population was particularly active (with $84 \%$ classified as active), which may serve as a protective factor against the development of musculoskeletal injuries (16).

The subject of musculoskeletal injuries related to the use of lead aprons has received little attention. Ross et al (9) compared three groups of internists and found that axial skeletal complaints were reported at a significantly higher frequency among interventional cardiologists who wore lead aprons, and at the least frequency among rheumatologists. Ross et al (9) found the lowest level of back injury among rheumatologists, indicating that there is less risk among internists who do not perform procedures. Wearing a $15 \mathrm{lb}(6.08 \mathrm{~kg})$ lead apron can induce pressures of $300 \mathrm{lb} / \mathrm{square}$ inch $\left(21 \mathrm{~kg} / \mathrm{cm}^{2}\right)$ in the intervertebral disk space. Modifying the weight by dividing the lead into two pieces decreases the pressure on the lumbar spine and cervical disks (17). Fortunately, lighter aprons are now available; however, the proportion of ERCP endoscopists who use them is not known.

Ergonomic considerations are very important. The majority of respondents performed ERCP in areas with poor ergonomic design. Early endoscopy literature recommended using a fluoroscopy table with an adjustable height and the ability to tilt laterally (19). We agree with this recommendation and also suggest that video and fluoroscopy monitors should be placed side by side at a height such that the operators' eyes are three-quarters of the way up the screen (Figure 3) to minimize eye strain and unnecessary neck tor- 


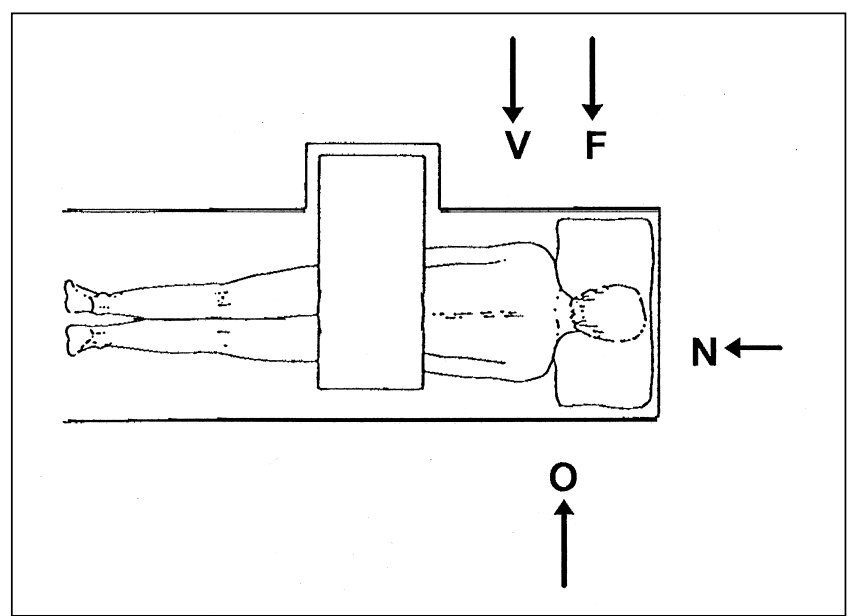

Figure 3) Optimal design of endoscopic retrograde cholangiopancreatography facilities. F Fluoroscopy screen; N Nurse; O Operator; $\mathrm{V}$ Video screen

sion (20). Similar recommendations have been validated by the Health and Safety Guidelines for Computer Use developed by the Massachusetts Institute of Technology (20). Also, ERCPs are often performed in cramped radiology facilities. Improved ergonomic design maximizes space and promotes proper posture. Finally, antifatigue matting should be used when endoscopists perform several ERCPs in succession. This floor padding reduces pressure on the spine during prolonged standing and delays the fatigue process of muscles.

\section{REFERENCES}

1. Ando S, Ono Y, Shimaoka M, et al. Associations of self estimated workloads with musculoskeletal symptoms among hospital nurses. Occup Environ Med 2000;57:211-6.

2. Akesson I, Johnsson B, Rylander L, Moritz U, Skerfving S. Musculoskeletal disorders among female dental personal - clinical examination and a 5-year follow-up study of symptoms. Int Arch Occup Environ Health 1999;72:395-403.

3. Wolny K, Shaw L, Verougstraete S. Repetitive strain injuries in dentistry. Ont Dent 1999;76:13-9.

4. Rossi A, Marino G, Barbier L, et al. Backache from exertion in health personnel of the Instituti Ortopedici Rizzoli in Bologna. A case control study of the injury phenomenon in the 10 year period of 1987-1996. Epidemiol Prev 1999;23:98-104.

5. Murphy DC. Ergonomics and dentistry. NY State Dent J 1997;63:30-4.

6. Mercer RB, Marcella CP, Carney DK, McDonald RW. Occupational health hazards to the ultrasonographer and possible prevention. J Am Soc Echocardiogr 1997;10:363-6.

7. Mital A. Recognizing musculoskeletal injury hazards in the upper extremities and lower back. Occup Health Saf 1997;66:91-9.

8. Moore B, van Sonennenberg E, Casola G, Novelline RA. The relationship between back pain and lead apron use in radiologists. AJR Am J Roentgenol 1992;158:191-3.

9. Ross AM, Jerome S, Borenstein D, Jenkins E, Cho S. Prevalence of spinal disc disease among interventional cardiologists. Am J Cardiol 1997;79:68-70.

10. Barkin JS, Lehman GA, Myerburg RJ, Fisher AH, Kapel RC, Reiner DK. Endoscopy procedures: an occupational hazard for gastroenterologists. Gastroenterology 1995;108:A437. (Abst)
Among the strategies to prevent musculoskeletal injures, particularly low back injuries, ergonomic job design is considered to be the most effective means of prevention (21).

We did not assess disability claims among the respondents, and presumably physicians who have been significantly injured would no longer perform ERCP. We did not assess and are unaware of any legal actions against hospitals in Canada regarding ERCPs.

\section{CONCLUSIONS}

There is extensive literature to support the notion that the increase in occupational back and upper extremity injuries has become a major socioeconomic problem (7). To prevent these disabling and costly conditions successfully, more research is needed in all professions to determine where environmental risks exist, and more effort must be put into implementing preventive strategies.

Our results indicate that ERCP endoscopists may be at considerable risk for the development of occupational musculoskeletal injuries. The preventive measures discussed in this paper (Table 3, Figure 3) should be implemented to minimize risk. The survey used in this study was sent only to ERCP endoscopists practising in Canada. A limitation of our study is that musculoskeletal complaints among ERCP endoscopists were not compared with those of endoscopists who do not perform ERCP. Further studies are needed in Canada and other countries to investigate this issue, which may lead to improved working conditions for ERCP endoscopists.
11. Hirschowitz BI. The cost of doing business: occupational hazards for the endoscopists. Endoscopy 1994;26:559-61.

12. Buschbacher RM, Campbell WW, Wirth B. Endoscopists tendonitis: an overuse syndrome of the flexor pollicis longus. Arch Phys Med Rehabil 1991;72:825. (Abst)

13. Calebaugh DL. Afflicted endoscopists. Gastrointest Endosc. 1990;36:633. (Lett)

14. Buschbacher R. Overuse syndromes among endoscopists. Endoscopy 1994;26:539-44.

15. Siegel JH, Kasmin FE, Cohen SA. Health hazards and endoscopy: the known and newly experienced - a personal report. Endoscopy 1994;26:545-8.

16. Shelerud R. Epidemiology of occupational low back pain. Occup Med 1998;13:1-16.

17. Khalil TM, Abdel-Moty E. Ergonomics in Back Pain: A Guide to Prevention and Rehabilitation. New York: Van Nostrand Reinhold, 1993.

18. Fast C. Repetitive strain injury: an overview of the condition and its implications for occupational therapy practice. Can J Occup Ther 1995;62:119-26.

19. Salmon PR. Fiber-optic Endoscopy. New York: Grune \& Stratton, 1974:15.

20. MIT Information Systems. Repetitive Strain Injuries (RSI) [Health and Safety Guidelines for Computer Use], March 3, 1999. $<$ http://web.mit.edu/is/pubs/is-13/rsi.html > Version current at January 2, 2002.

21. Kaplansky BD, Wei FY, Reecer MV. Prevention strategies for occupational low back pain. Occup Med 1998;13:33-42. 


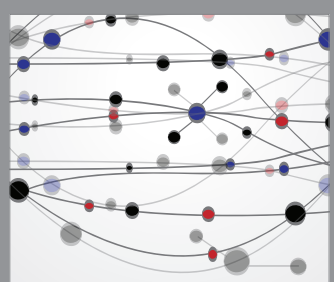

The Scientific World Journal
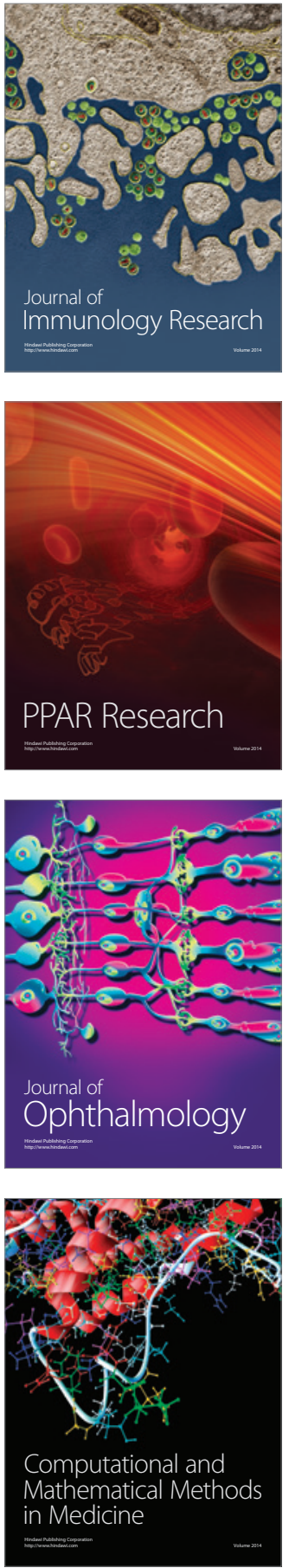

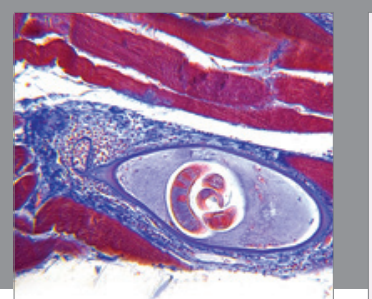

Gastroenterology Research and Practice

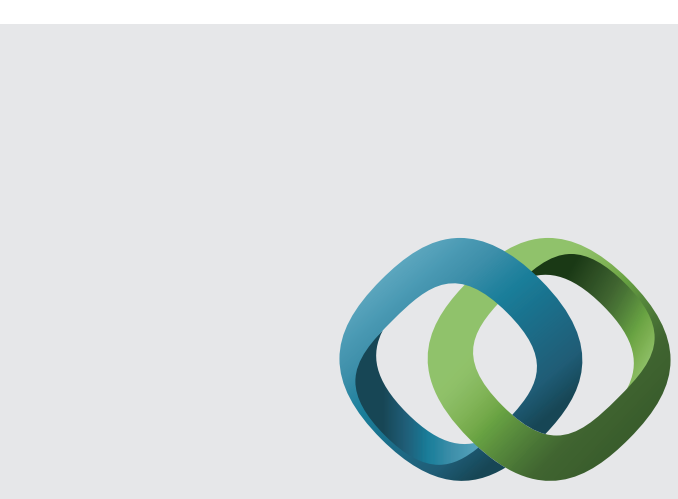

\section{Hindawi}

Submit your manuscripts at

http://www.hindawi.com
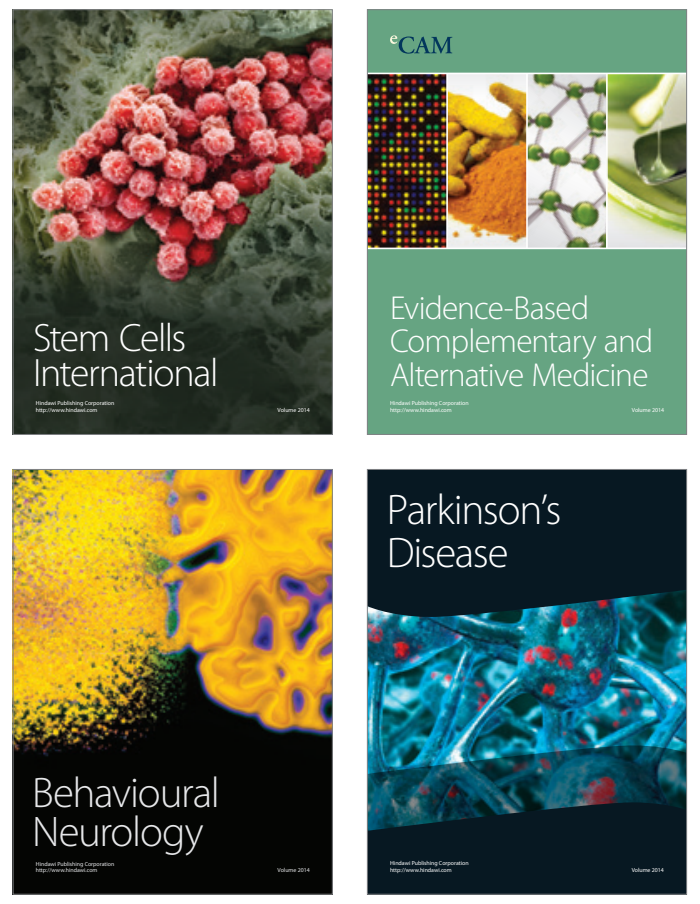
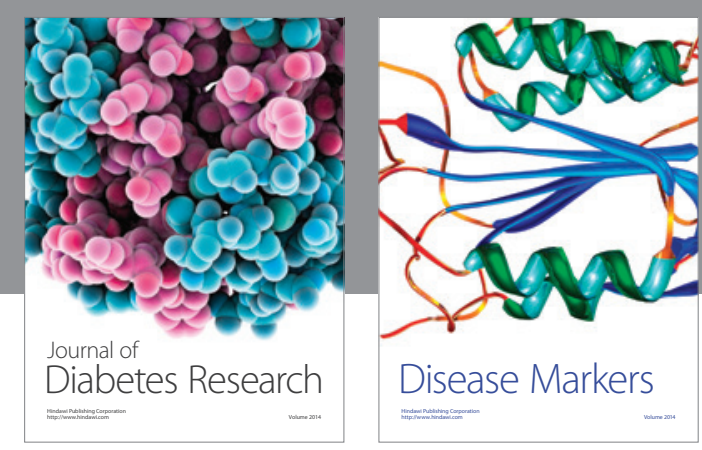

Disease Markers
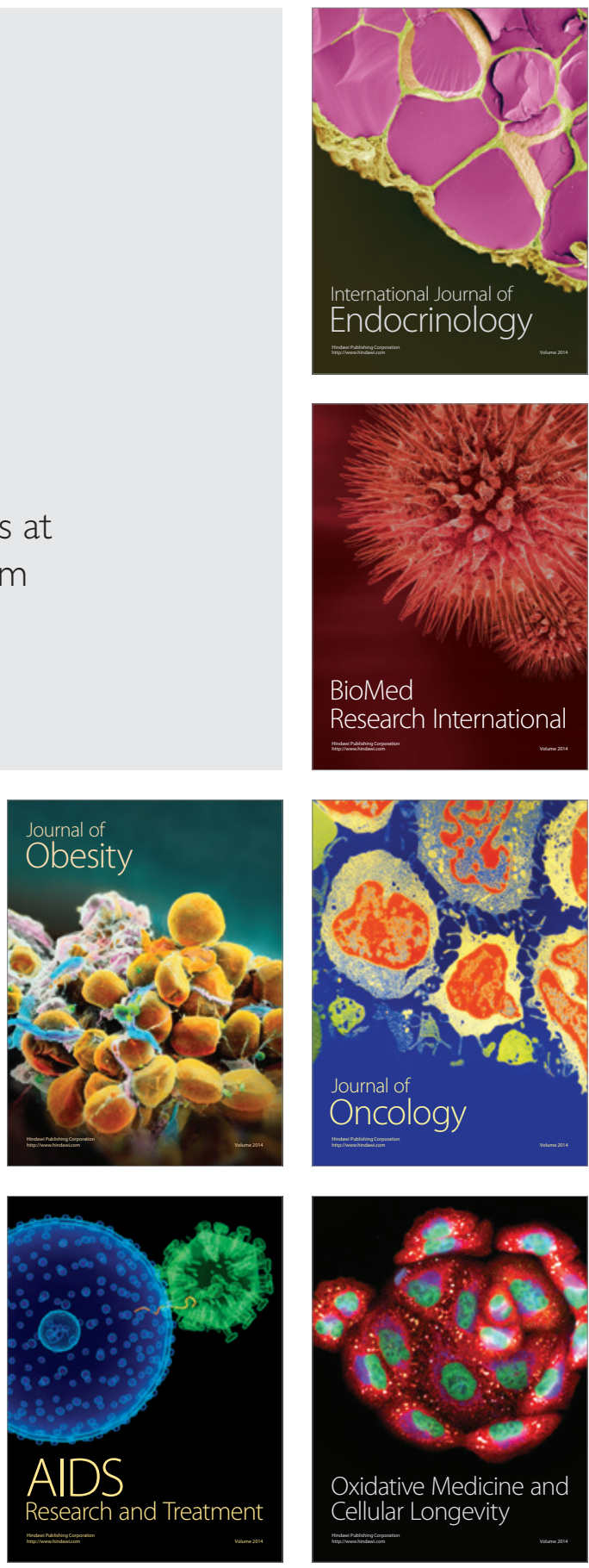